\title{
Exploratory Factor Analysis of the Adolescent Version of the General Behavior Inventory in Korean Youth
}

\author{
Han-Sung Lee, Yejin Kwon, Seung-Hyun Shon, Kee Jeong Park, and Hyo-Won Kim \\ Department of Psychiatry, Asan Medical Center, University of Ulsan College of Medicine, Seoul, Korea
}

Objectives: We examined the factor structure of the Adolescent version of the General Behavior Inventory (A-GBI) for Koreans.

Methods: We retrospectively reviewed the medical records of 220 adolescents (age, 12-18 years) who completed the A-GBI through the Department of Psychiatry at Asan Medical Center, Seoul, Korea, from October 2011 to December 2018. Caregivers of the study participants completed the Parent version of the GBI (P-GBI) 10-item Mania Scale. The adolescents were evaluated based on the A-GBI, Children's Depression Inventory (CDI), and Revised-Children's Manifest Anxiety Scale (RCMAS). Subsequently, an exploratory factor analysis (EFA) using the maximum likelihood method with direct oblimin rotation and correlation analyses with other scales were performed.

Results: The EFA identified a two-factor structure as having the best fit: factor I included depressive symptoms and factor II included hypomanic/biphasic symptoms. Factor I was very strongly correlated with the A-GBI depressive subscale $(\mathrm{r}=0.990, \mathrm{p}<0.001)$ and strongly correlated with CDI $(r=0.764, \mathrm{p}<0.001)$ and RCMAS $(\mathrm{r}=0.666, \mathrm{p}<0.001)$. Factor II was also very strongly correlated with the AGBI hypomanic/biphasic subscale $(\mathrm{r}=0.877, \mathrm{p}<0.001)$ and weakly correlated with CDI $(\mathrm{r}=0.274, \mathrm{p}<0.001)$ and $\mathrm{RCMAS}(\mathrm{r}=0.332$, $\mathrm{p}<0.001)$.

Conclusion: The above findings support a two-dimensional model of mood symptoms in Korean youth.

Key Words: Adolescent; Bbipolar disorder; Depression; Factor analysis.

Received: June 14, 2019 / Revision: August 5, 2019 / Accepted: August 13, 2019

Address for correspondence: Hyo-Won Kim, Department of Psychiatry, Asan Medical Center, University of Ulsan College of Medicine, 88 Olympic-ro 43gil, Songpa-gu, Seoul 05505, Korea

Tel: +82-2-3010-3414, Fax: +82-2-485-8381, E-mail: shingubi@amc.seoul.kr

\section{INTRODUCTION}

Childhood and adolescent depression is a mood disorder characterized by persistent depressed mood and hopelessness, mood swings, and irritability [1]. The disorder is relatively common with a prevalence rate of approximately $12 \%$, and it is known to have a chronic course with repeated periods of worsening and remission [2]. The rate of depressive disorder in youths is increasing annually in Korea, as it was reported in 2016 that $20.9 \%$ of male adolescents and $30.5 \%$ of female adolescents in Korea experienced depression [3]. Furthermore, children and adolescents with depressive disorders are more likely to have bipolar disorder, conduct disorder, drug abuse, and relationship problems, and also have increased risk for suicide and self-harm [1].

Compared to bipolar disorder in adulthood, bipolar disorder in childhood and adolescence is associated with shorter episodes, fewer symptom-free periods, higher level of irritability and more frequent mixed episodes, and shows a com-

This is an Open Access article distributed under the terms of the Creative Commons Attribution Non-Commercial License (https://creativecommons.org/licenses/by-nc/4.0) which permits unrestricted non-commercial use, distribution, and reproduction in any medium, provided the original work is properly cited. plex cycling pattern between depression and mania [4]. It is reported that bipolar disorder in youths is often accompanied by other psychiatric disorders such as attention-deficit/hyperactivity disorder (ADHD), disruptive behavioral disorder, and anxiety disorder [5]. It is also known that adolescent bipolar disorder causes difficulties in academics and in maintaining relationships with family and friends, and increases the risk for completed suicide $[6,7]$.

As discussed above, mood symptoms in youths pose higher risks for functional deterioration and behavioral problem, as well as other psychiatric comorbidities. Therefore, appropriate evaluation of mood symptoms and early diagnosis of depressive and bipolar disorders in youths are important in risk assessment and intervention. However, the mood symptoms in youths are known to be more difficult to assess than the symptoms manifested by adults. The Beck Depression Inventory (BDI) and Children's Depression Inventory (CDI), which are commonly used for the assessment of mood symptoms, are thought to be limited in evaluating depressive symptoms during childhood and adolescence, a period characterized by mood fluctuation and irritability [8].

Depue et al. [9] proposed a two-dimensional model of mood 
symptoms, and developed the General Behavior Inventory (GBI), which consists of depressive subscale and hypomanic/ biphasic subscale. The parent version of the GBI (P-GBI) and adolescent version of the GBI (A-GBI), which are modifications of the GBI, evaluate not only depressed mood but also irritability, mood swings, hypomanic symptoms, and behavioral problems, and are effective in screening and assessing depressive and bipolar disorders in youths [10]. In a study that evaluated the diagnostic usefulness and reliability of the Korean version of the A-GBI, the depressive and hypomanic/ biphasic subscales showed significant differences between adolescents with bipolar and depressive disorders, and the depressive subscale was correlated with other diagnostic tools for mood disorder [11]. However, the study did not explore the existence of common factors among individual items; furthermore, it did not examine whether the two-dimensional model still holds in Korean youths' A-GBI results.

Accordingly, the present study was conducted to identify common factors among the individual items of the Korean version of the A-GBI and investigate whether the two-dimensional model fits mood symptoms in Korean youths by comparing the latent factors with those of the English version of the A-GBI.

\section{METHODS}

\section{Subjects}

Study subjects were adolescents aged between 12 and 18 years who were evaluated with the A-GBI at the Department of Pediatric Psychiatry, Asan Medical Center in Seoul between October 12, 2011 and December 31, 2018. Of a total of $392 \mathrm{el}-$ igible adolescents, those with the following conditions were excluded from the study: intelligence quotient (IQ) lower than $80(\mathrm{n}=61)$, diagnosis of autism spectrum disorder $(\mathrm{n}=6)$, psychosis $(\mathrm{n}=29)$ or organic brain syndrome $(\mathrm{n}=13)$, individual AGBI item scores not available or missing values in $10 \%$ or more of the items $(n=62)$, and clinical information not available $(\mathrm{n}=1)$. Finally, the data from the remaining 220 subjects were analyzed. Of the 220 subjects, 90 (40.9\%) were boys and 130 (59.1\%) were girls. The study was approved by the Institutional Review Board at the Asan Medical Center. Requirement for informed consents was waived because it was a retrospective study (IRB No. 2019-0129).

\section{Study design}

In this retrospective study, subjects' medical records were reviewed to collect demographic and clinical data including age and sex. The diagnosis and psychiatric comorbidities were confirmed retrospectively based on the reported symptoms in the medical records in accordance with Diagnostic and Sta- tistical Manual of Mental Disorders Fifth Edition. The subjects were classified into the following groups: bipolar disorder, depressive disorder, or non-mood disorder. The bipolar disorder group included subjects diagnosed with bipolar depression, bipolar mania, or bipolar disorder not otherwise specified (BD-NOS), and the depressive disorder group included subjects diagnosed with unipolar depression, dysthymia, or adjustment disorder with depressed mood. Subjects without any mood disorders were assigned to the non-mood disorder group.

\section{Assessment tools}

\section{Adolescent and parent versions of General Behavior Inventories}

A-GBI is a modification of the GBI [9] for use in the youth [12]. In the present study, the Korean version standardized by Lee et al. [11] was used. A-GBI is a self-administered scale and consists of 46 items in the depressive subscale and 28 in the hypomanic/biphasic subscale, for a total of 76 items. Each item is scored between 0 and 3 points, and the subscales are scored separately; the test score is computed by adding the subscale scores. In this study, individual item scores were submitted to factor analysis, and the subscale scores were used in other analysis. P-GBI was revised by Youngstrom et al. [13], based on GBI; it is composed of 10 items, in which the parent assesses the child's mood symptoms.

\section{Revised Children's Manifest Anxiety Scale}

Reynolds and Richmond [14] developed Revised Children's Manifest Anxiety Scale (RCMAS) to assess anxiety in children, by revising existing anxiety assessment tools. In this study, the Korean version of the scale standardized by Choi and Cho [15] is used. The scale has a total of 37 items regarding symptoms of anxiety, each requiring a "yes" or "no" response. The total score is obtained by adding individual item scores. The higher the score, the higher the anxiety level.

\section{Children's Depression Inventory}

CDI was revised by Kovacs and Beck [16] from BDI [17], to assess the depression level in children. The Korean version of CDI translated by Cho and Lee [18] is used in this study. The tool consists of 27 items, and the child selects one of the three sentences presented in each item that most closely describes his/her symptoms. Individual items are scored between 0 and 2 points, and the total score is obtained by adding individual item scores. The higher the score, the higher the depression level. 


\section{Statistical analyses}

Analysis of variance was performed to examine betweengroup differences in demographic characteristics and the scale scores. Additionally, exploratory factor analysis (EFA) using maximum likelihood and direct oblinin rotation was conducted on A-GBI test results. Factor scores for each factor were computed using the regression method, and correlational analysis with Pearson correlation coefficients was applied to investigate the relationship between factor scores and scores in A-GBI, full scale IQ (FSIQ), RCMAS, CDI and PGBI. All statistical analyses were performed using SPSS 21.0 (IBM Corp., Armonk, NY, USA), and statistical significance was set at $\mathrm{p}<0.05$.

\section{RESULTS}

\section{Demographic characteristics (Table 1)}

Of the 220 subjects, 90 (40.9\%) were boys and 130 (59.1\%) were girls. Twenty-eight subjects were diagnosed with bipolar depression, 4 with bipolar mania, 21 with BD-NOS, 123 with unipolar depression, and 3 with dysthymia. Additionally, 2 were diagnosed with both unipolar depression and dysthymia, and 6 with adjustment disorder with depressed mood. Thirty-three subjects were not diagnosed with any mood disorder. Accordingly, 134 were classified into the depressive disorder group (age 15.4 \pm 1.5 year, 59 boys), 53 into the bipolar disorder group (age 15.4 \pm 1.7 year, 12 boys), and 33 into the non-mood disorder group (age 14.6 \pm 1.8 year, 19 boys). The subjects in the depressive disorder group were significantly older than those in the non-mood disorder group $(\mathrm{F}=3.55$, $\mathrm{p}=0.030$ ). With respect to sex, the proportion of girls was significantly higher in the bipolar disorder group than in the depressive disorder and non-mood disorder groups ( $\mathrm{F}=11.66$, $\mathrm{p}=0.003$ ). However, age or sex did not show a significant between-group difference after Bonferroni corrections.

Between-group difference was not significant in terms of FSIQ or P-GBI. However, depressive disorder and bipolar disorder groups scored significantly higher than the nonmood disorder group in RCMAS ( $\mathrm{F}=9.67, \mathrm{p}<0.001)$, CDI $(\mathrm{F}=10.97, \mathrm{p}<0.001)$, and A-GBI depressive subscale $(\mathrm{F}=15.53$, $\mathrm{p}<0.001)$. Particularly, A-GBI hypomanic/biphasic subscale score was the highest in the bipolar disorder group, followed by the depressive disorder and non-mood disorder groups, and the score was significantly different among the three groups $(\mathrm{F}=10.56, \mathrm{p}<0.001)$.

\section{Factor analysis on Adolescent version of the General Behavior Inventory}

First, it was confirmed that the A-GBI data were suitable for factor extraction using the Kaiser-Meyer-Olkin (KMO) measure of sampling adequacy (KMO value $=0.937)$, and the assumption of the absence of common factors in the 73 items was rejected based on the Bartlett test $\left(\chi^{2}=11011.964, \mathrm{df}=2628\right.$, $\mathrm{p}<0.001)$. Next, EFA with maximum likelihood estimation was

Table 1. Demographic and clinical characteristics of subjects

\begin{tabular}{|c|c|c|c|c|c|c|}
\hline & Depressive $(n=134)$ & Bipolar $(n=53)$ & Non-mood $(n=33)$ & F or $\chi^{2}$ & $\mathrm{p}$ & Post-hoc \\
\hline Age, years & $15.4 \pm 1.5$ & $15.4 \pm 1.7$ & $14.6 \pm 1.8$ & 3.55 & 0.030 & $\mathrm{D}>\mathrm{N}$ \\
\hline Gender, boys & $59(44)$ & $12(22.6)$ & $19(57.6)$ & 11.66 & 0.003 & $N, D>B$ \\
\hline \multicolumn{7}{|l|}{ Comorbidity } \\
\hline Anxiety disorders & $25(18.7)$ & $15(28.3)$ & $17(51.5)$ & 15.10 & 0.001 & $N>B, D$ \\
\hline SSD & $10(7.5)$ & $3(5.7)$ & $6(18.2)$ & 4.64 & 0.098 & \\
\hline ADHD & $7(5.2)$ & $3(5.7)$ & $8(24.2)$ & 13.34 & 0.001 & $N>B, D$ \\
\hline Tic disorder & $3(2.2)$ & $2(3.8)$ & $3(9.1)$ & 3.55 & 0.169 & \\
\hline Eating disorder & $4(3.0)$ & $2(3.8)$ & $4(12.1)$ & 5.19 & 0.075 & \\
\hline Conduct disorder/ODD & $4(3.0)$ & $1(1.9)$ & $4(12.1)$ & 6.50 & 0.039 & $N>B, D$ \\
\hline $\mathrm{FSIQ}$ & $102.0 \pm 13.9$ & $98.5 \pm 11.9$ & $98.9 \pm 12.5$ & 1.59 & 0.206 & \\
\hline RCMAS & $18.2 \pm 7.2$ & $19.4 \pm 7.6$ & $12.7 \pm 6.3$ & 9.67 & $<0.001$ & $D, B>N$ \\
\hline CDI & $22.0 \pm 8.9$ & $24.4 \pm 11.3$ & $14.9 \pm 8.0$ & 10.97 & $<0.001$ & $D, B>N$ \\
\hline \multicolumn{7}{|l|}{ A-GBI } \\
\hline Depressive & $59.7 \pm 31.8$ & $71.5 \pm 34.2$ & $32.4 \pm 28.3$ & 15.53 & $<0.001$ & $D, B>N$ \\
\hline Hypomanic/biphasic & $23.7 \pm 14.1$ & $30.8 \pm 17.3$ & $15.7 \pm 14.9$ & 10.56 & $<0.001$ & $B>D>N$ \\
\hline P-GBI & $8.0 \pm 6.0$ & $8.6 \pm 5.4$ & $6.3 \pm 5.1$ & 1.22 & 0.298 & \\
\hline
\end{tabular}

Data are meantstandard deviation or $\mathrm{n}(\%)$ values. Multiple comparison corrected significance level: $\mathrm{p}<0.003$. ADHD: attentiondeficit/hyperactivity disorder, A-GBI: adolescent version of the General Behavioral Inventory, B: bipolar disorder group, CDI: Children's Depression Inventory, D: depressive disorder group, FSIQ: full scale intelligence quotient, N: non-mood disorder group, ODD: oppositional defiant disorder, P-GBI: parent version of the General Behavioral Inventory, RCMAS: Revised Children's Manifest Anxiety Scale, SSD: somatic symptom disorder 
Table 2. Goodness-of-fit indices in the exploratory factor analysis

\begin{tabular}{ccccc}
\hline Factor model & $\chi^{2}$ & $\mathrm{df}$ & $\mathrm{p}$ & RMSEA \\
\hline 1 & 4775.826 & 2555 & $<0.001$ & 0.120 \\
2 & 3973.613 & 2483 & $<0.001$ & 0.091 \\
3 & 3668.534 & 2412 & $<0.001$ & 0.085 \\
4 & 3416.968 & 2342 & $<0.001$ & 0.080 \\
5 & 3195.788 & 2273 & $<0.001$ & 0.075 \\
\hline
\end{tabular}

RMSEA: root mean square error of approximation performed to identify an appropriate factor model (Table 2), and a two-factor model was found to have the best fit to the data. An EFA specifying two factors and using an direct oblinin rotation was performed (Table 3), and items with a factor loading value of 0.4 or lower were removed. Factor I was interpreted as a factor measuring depression level, similar to AGBI depressive subscale, and Factor II was interpreted as a

Table 3. The two factor solution of the A-GBI

\begin{tabular}{|c|c|c|c|c|c|}
\hline Item & Factor I & Factor II & Depressive* & $\begin{array}{l}\text { Hypomanic/ } \\
\text { Biphasic }^{\dagger}\end{array}$ & Questions \\
\hline 63 & 0.96 & & + & & $\begin{array}{l}\text { Have there been periods lasting several days or more when you were so } \\
\text { down in the dumps that you thought you might never snap out of it? }\end{array}$ \\
\hline 72 & 0.95 & & + & & Have there been periods of time when you felt a persistent sense of gloom? \\
\hline 62 & 0.92 & & + & & $\begin{array}{l}\text { Have you had periods when it seemed that the future was hopeless and } \\
\text { things could not improve? }\end{array}$ \\
\hline 56 & 0.90 & & + & & $\begin{array}{l}\text { Have there been times of several days or more when you really got down on } \\
\text { yourself and felt worthless? }\end{array}$ \\
\hline 23 & 0.90 & & + & & $\begin{array}{l}\text { Have there been times of several days or more when you were so sad that it } \\
\text { was quite painful for you, or you felt that you couldn't stand it? }\end{array}$ \\
\hline 50 & 0.86 & & + & & $\begin{array}{l}\text { Have you had sad and depressed periods lasting several days or more when } \\
\text { you also felt much more anxious or tense (jittery, nervous, uptight) than usual } \\
\text { (other than related to the menstrual cycle)? }\end{array}$ \\
\hline 73 & 0.86 & & + & & Have there been times when you felt that you would be better off dead? \\
\hline 34 & 0.85 & & + & & $\begin{array}{l}\text { Have there been long periods over the last year when you felt sad, } \\
\text { depressed, or irritable most of the time? }\end{array}$ \\
\hline 55 & 0.83 & & + & & $\begin{array}{l}\text { Have there been times when upsetting or bad thoughts kept going through } \\
\text { your mind and you couldn't stop them? }\end{array}$ \\
\hline 16 & 0.82 & & + & & $\begin{array}{l}\text { Have you had long periods in which you felt that you couldn't enjoy life as } \\
\text { easily as other people? }\end{array}$ \\
\hline 45 & 0.82 & & + & & $\begin{array}{l}\text { Over the past year, have there been times of several days or more when you } \\
\text { were so down that nothing (not even friends or good news) could cheer } \\
\text { you up? }\end{array}$ \\
\hline 3 & 0.80 & & + & & $\begin{array}{l}\text { Have you become sad, depressed, or irritable for several days or more with } \\
\text { out really understanding why? }\end{array}$ \\
\hline 14 & 0.79 & & + & & $\begin{array}{l}\text { Have you had periods of sadness and depression when almost everything } \\
\text { gets on your nerves and makes you irritable or angry (other than related to } \\
\text { the menstrual cycle)? }\end{array}$ \\
\hline 32 & 0.79 & & + & & $\begin{array}{l}\text { Over the past year, have there been times when you looked back over your } \\
\text { life and could see only failures or hardships? }\end{array}$ \\
\hline 68 & 0.79 & & + & & $\begin{array}{l}\text { Have you had long periods when you were down and depressed, interrupted } \\
\text { by brief periods when your mood was normal or slightly happy? }\end{array}$ \\
\hline 47 & 0.78 & & + & & $\begin{array}{l}\text { Have there been times when you hated yourself or felt that you were stupid, } \\
\text { ugly, unlovable, or useless? }\end{array}$ \\
\hline 69 & 0.77 & & + & & $\begin{array}{l}\text { Have there been times of several days or more when you have struggled } \\
\text { to control an urge to cry, have had frequent crying spells, or found yourself } \\
\text { crying without really understanding why (other than related to the menstrual } \\
\text { cycle)? }\end{array}$ \\
\hline 9 & 0.75 & & + & & $\begin{array}{l}\text { Have there been periods lasting several days or more when you lost almost } \\
\text { all interest in people close to you and spent long times by yourself? }\end{array}$ \\
\hline 49 & 0.74 & & + & & $\begin{array}{l}\text { Have there been times of a day or more when you had no feelings or } \\
\text { emotions and seemed cut off from other people? }\end{array}$ \\
\hline
\end{tabular}


Table 3. The two factor solution of the A-GBI (continued)

\begin{tabular}{|c|c|c|c|c|c|}
\hline Item & Factor I & Factor II & Depressive* & $\begin{array}{c}\text { Hypomanic/ } \\
\text { Biphasic }^{\dagger}\end{array}$ & Questions \\
\hline 20 & 0.72 & & + & & $\begin{array}{l}\text { Have there been periods lasting several days or more when you spent much } \\
\text { of your time brooding about unpleasant things that have happened? }\end{array}$ \\
\hline 41 & 0.70 & & + & & $\begin{array}{l}\text { Have you had periods of several days or more when it was difficult or almost } \\
\text { impossible to think and your mind felt sluggish, stagnant, or "dead"? }\end{array}$ \\
\hline 71 & 0.70 & & + & & $\begin{array}{l}\text { Have you found yourself at times feeling fearful or suspicious of your } \\
\text { environment or people around you? }\end{array}$ \\
\hline 13 & 0.67 & & + & & $\begin{array}{l}\text { Have there been times when you lost almost all interest in the things that you } \\
\text { usually like to do (such as hobbies, school, work, entertainment)? }\end{array}$ \\
\hline 35 & 0.67 & & & + & $\begin{array}{l}\text { Has it seemed that you experience both pleasurable and painful emotions } \\
\text { more intensely than other people? }\end{array}$ \\
\hline 52 & 0.66 & & + & & $\begin{array}{l}\text { Have you had periods of sadness and depression when, for several days or } \\
\text { more, it took you over an hour to get to sleep at night, even though you } \\
\text { were very tired? }\end{array}$ \\
\hline 22 & 0.63 & & & + & $\begin{array}{l}\text { Have you had periods of extreme happiness and intense energy lasting } \\
\text { several days or more when you also felt much more anxious or tense (jittery, } \\
\text { nervous, uptight) than usual (other than related to the menstrual cycle)? }\end{array}$ \\
\hline 36 & 0.63 & & + & & $\begin{array}{l}\text { Have there been periods of several days or more when you felt guilty and } \\
\text { thought you deserved to be punished for something you had or had not } \\
\text { done? }\end{array}$ \\
\hline 18 & 0.63 & & + & & $\begin{array}{l}\text { Have there been times of several days or more when you were so tired } \\
\text { and worn out that it was very difficult or even impossible to do your normal } \\
\text { everyday activities (not including times of intense exercise, physical illness, } \\
\text { or heavy work schedules)? }\end{array}$ \\
\hline 26 & 0.61 & & + & & $\begin{array}{l}\text { Have you had periods when you were so down that you found it hard to start } \\
\text { talking or that talking took too much energy? }\end{array}$ \\
\hline 1 & 0.60 & & + & & $\begin{array}{l}\text { Have there been periods, over the last year, when it was almost impossible to } \\
\text { make small decisions even though this may not be generally true of you? }\end{array}$ \\
\hline 6 & 0.59 & & + & & Have people said that you looked sad or lonely? \\
\hline 57 & 0.59 & & & + & $\begin{array}{l}\text { Have there been times when you had blank spells in which your activities } \\
\text { were interrupted, and you did not know what was going on around you? }\end{array}$ \\
\hline 59 & 0.58 & & + & & $\begin{array}{l}\text { Have there been periods of several days or more when you were slowed } \\
\text { down and couldn't move as quickly as usual? }\end{array}$ \\
\hline 40 & 0.58 & & & + & $\begin{array}{l}\text { Have you found that your feelings or energy are generally up or down, but } \\
\text { rarely in the middle? }\end{array}$ \\
\hline 12 & 0.57 & & + & & $\begin{array}{l}\text { Have there been times when your memory or concentration seemed es } \\
\text { pecially poor and you found it difficult, for example, to read or follow a TV } \\
\text { program, even though you tried? }\end{array}$ \\
\hline 19 & 0.57 & & & + & $\begin{array}{l}\text { Has your mood or energy shifted rapidly back and forth from happy to sad or } \\
\text { high to low? }\end{array}$ \\
\hline 28 & 0.57 & & + & & $\begin{array}{l}\text { Have there been periods other than when you were physically ill that you } \\
\text { had more than one of the following: (a) headaches or feelings of tightness, } \\
\text { pressure, or "wooziness" in your head; (b) dizziness; (c) constipation or } \\
\text { diarrhea; (d) aches and pains; (e) nausea, vomiting, or stomach aches; (f) } \\
\text { blurred vision; (g) trembling or shaking hands; or (h) feeling too hot or too } \\
\text { cold? }\end{array}$ \\
\hline 2 & 0.56 & & & + & $\begin{array}{l}\text { Have you found your enjoyment in being with people changes -- from times } \\
\text { when you enjoy them immensely and want to be with them all the time, to } \\
\text { times when you do not want to see them at all? }\end{array}$ \\
\hline
\end{tabular}


Table 3. The two factor solution of the A-GBI (continued)

\begin{tabular}{|c|c|c|c|c|c|}
\hline Item & Factor I & Factor II & Depressive* & $\begin{array}{l}\text { Hypomanic/ } \\
\text { Biphasic }^{\dagger}\end{array}$ & Questions \\
\hline 39 & 0.53 & & + & & $\begin{array}{l}\text { Have there been times when you were feeling low and depressed, and you } \\
\text { also had to struggle very hard to control inner feelings of rage or an urge to } \\
\text { smash or destroy things? }\end{array}$ \\
\hline 10 & 0.52 & & + & & $\begin{array}{l}\text { Have you had periods of several days or more when food seemed rather } \\
\text { flavorless and you didn't enjoy eating at all? }\end{array}$ \\
\hline 33 & 0.48 & & + & & $\begin{array}{l}\text { Have you experienced times of several days or more when you felt as if you } \\
\text { were moving in slow motion? }\end{array}$ \\
\hline 66 & 0.48 & & & + & $\begin{array}{l}\text { Have then been times when you began many new activities with lots of } \\
\text { enthusiasm and then found yourself quickly losing interest in them? }\end{array}$ \\
\hline 29 & 0.46 & 0.40 & + & & $\begin{array}{l}\text { Have you experienced periods of several days or more when were feeling } \\
\text { down and depressed, and you also were physically restless, unable to sit still, } \\
\text { and had to keep moving or jumping from one activity to another? }\end{array}$ \\
\hline 5 & 0.46 & & + & & $\begin{array}{l}\text { Have there been periods of several days or more when you felt that you } \\
\text { needed more sleep, even though you slept longer at night or napped more } \\
\text { during the day (not including times of exercise, physical illness, or heavy } \\
\text { work schedules)? }\end{array}$ \\
\hline 37 & 0.46 & & + & & $\begin{array}{l}\text { Have you had times of several days or more when you woke up frequently } \\
\text { or had trouble staying asleep during the middle of the night? }\end{array}$ \\
\hline 70 & 0.45 & & + & & $\begin{array}{l}\text { Have there been times of several days or more when almost all sexual interest } \\
\text { was lost? }\end{array}$ \\
\hline 42 & 0.44 & & & + & $\begin{array}{l}\text { Have there been times when you had a strong urge to do something } \\
\text { mischievous, destructive, risky, or shocking? }\end{array}$ \\
\hline 21 & 0.44 & & + & & $\begin{array}{l}\text { Have there been times when you felt that you were physically cut off from } \\
\text { other people or from yourself, or felt as if you were in a dream, or felt that } \\
\text { the world looked different or had changed in some way? }\end{array}$ \\
\hline 8 & 0.41 & & & + & $\begin{array}{l}\text { Have there been periods of several days or more when you could not keep } \\
\text { your attention on any one thing for more than a few seconds, and your } \\
\text { mind jumped rapidly from one thought to another or to things around you? }\end{array}$ \\
\hline 25 & 0.40 & & + & & $\begin{array}{l}\text { Have there been times of several days or more when you wake up much too } \\
\text { early in the morning and have problems getting back to sleep? }\end{array}$ \\
\hline 60 & 0.40 & & + & & $\begin{array}{l}\text { Have you experienced weight changes (increases, decreases, or both) } \\
\text { of five pounds or more in short periods of time (three weeks or less), not } \\
\text { including changes due to physical illness, menstruation, exercise, or dieting? }\end{array}$ \\
\hline 38 & & 0.63 & & + & $\begin{array}{l}\text { Have you had periods of extreme happiness and high energy lasting } \\
\text { several days or more when what you saw, heard, smelled, tasted, } \\
\text { or touched seemed vivid or intense? }\end{array}$ \\
\hline 43 & & 0.60 & & + & $\begin{array}{l}\text { Have there been periods of several days or more when your thinking was so } \\
\text { clear and quick that it was much better than most other people's? }\end{array}$ \\
\hline 64 & & 0.57 & & + & $\begin{array}{l}\text { Have you had times when your thoughts and ideas came so fast that you } \\
\text { couldn't get them all out, or they came so quickly others complained that } \\
\text { they couldn't keep up with your ideas? }\end{array}$ \\
\hline 30 & & 0.56 & & + & $\begin{array}{l}\text { Have there been times lasting several days or more when you felt you must } \\
\text { have lots of excitement, and you actually did a lot of new or different things? }\end{array}$ \\
\hline 46 & & 0.53 & & + & $\begin{array}{l}\text { Have there been times of several days or more when you felt that you were } \\
\text { a very important person or that your abilities or talents were better than } \\
\text { most other people's? }\end{array}$ \\
\hline 48 & & 0.52 & & + & $\begin{array}{l}\text { Have you found that your thinking changes greatly - that there are periods } \\
\text { of several days or more when you think better than most people, and other } \\
\text { periods when your mind doesn't work well at all? }\end{array}$ \\
\hline
\end{tabular}


Table 3. The two factor solution of the A-GBI (continued)

\begin{tabular}{|c|c|c|c|c|c|}
\hline Item & Factor I & Factor II & Depressive* & $\begin{array}{c}\text { Hypomanic/ } \\
\text { Biphasic }^{\dagger}\end{array}$ & Questions \\
\hline 31 & & 0.52 & & + & $\begin{array}{l}\text { Have you had periods of extreme happiness and intense energy (clearly } \\
\text { more than your usual self) when, for several days or more, it took you over } \\
\text { an hour to get to sleep at night? }\end{array}$ \\
\hline 53 & & 0.50 & & + & $\begin{array}{l}\text { Have you had periods lasting several days or more when you felt depressed } \\
\text { or irritable, and then other periods of several days or more when you felt } \\
\text { extremely high, elated, and overflowing with energy? }\end{array}$ \\
\hline 15 & & 0.48 & & + & $\begin{array}{l}\text { Have there been times of several days or more when you did not feel the } \\
\text { need for sleep and were able to stay awake and alert for much longer than } \\
\text { usual because you were full of energy? }\end{array}$ \\
\hline 27 & & 0.47 & & + & $\begin{array}{l}\text { Have there been times of several days or more when, although you were } \\
\text { feeling unusually happy and intensely energetic (clearly more than your } \\
\text { usual self), you also had to struggle very hard to control inner feelings of } \\
\text { rage or an urge to smash or destroy things? }\end{array}$ \\
\hline 54 & & 0.46 & & + & $\begin{array}{l}\text { Have there been periods when, although you were feeling unusually happy } \\
\text { and intensely energetic, almost everything got on your nerves and made } \\
\text { you irritable or angry (other than related to the menstrual cycle?) }\end{array}$ \\
\hline 17 & & 0.42 & & + & $\begin{array}{l}\text { Have you had periods of several days or more when you wanted to be with } \\
\text { people so much of the time that they asked you to leave them alone for a } \\
\text { while? }\end{array}$ \\
\hline
\end{tabular}

All loadings $\geq 0.40$ appear in the table. Loadings for items $4,7,11,24,44,51,58,61,65$, and 67 were all below 0.40 . ${ }^{*}$ items included in Depressive subscales in original A-GBI, titems included in hypomanic/biphasic subscales in original A-GBI. A-GBI: adolescent version of General Behavioral Inventory

Table 4. Correlations of Factor I and II scores with mood and anxiety scales

\begin{tabular}{lcccc}
\hline & Factor I & Factor II & A-GBI depressive & A-GBI hypomanic/biphasic \\
\hline Factor I & 1 & $0.477^{\dagger}$ & $0.990^{\dagger}$ & $0.800^{\dagger}$ \\
Factor II & $0.477^{\dagger}$ & 1 & $0.517^{\dagger}$ & $0.877^{\dagger}$ \\
RCMAS & $0.666^{\dagger}$ & $0.332^{\dagger}$ & $0.664^{\dagger}$ & $0.570^{\dagger}$ \\
CDI & $0.764^{\dagger}$ & $0.274^{\dagger}$ & $0.770^{\dagger}$ & $0.550^{\dagger}$ \\
P-GBI & $0.241^{*}$ & $0.255^{*}$ & $0.266^{\dagger}$ & $0.322^{\dagger}$ \\
\hline
\end{tabular}

${ }^{*} p<0.01,{ }^{\dagger} p<0.001$. A-GBI: adolescent version of General Behavioral Inventory, CDI: Children's Depression Inventory, P-GBI: parent version of General Behavioral Inventory, RCMAS: Revised Children's Manifest Anxiety Scale

factor assessing hypomanic/biphasic symptoms.

Factor I included a total of 51 items, 42 out of 46 items in the A-GBI depressive subscale and 9 out of 28 items in the AGBI hypomanic/biphasic subscale. Factor II included a total of 13 items, 1 from the depressive subscale and 12 from the hypomanic/biphasic subscale. Items $4,7,11,24,44,51,58,61$, 65 , and 67 were excluded because the factor loading value was 0.4 or lower.

To eliminate the influence of comorbidity on the EFA, additional round of analysis was performed on the group of subjects without a comorbidity ( $\mathrm{n}=119)$ (Supplementary Table 1 in the online-only Data Supplement). The data of this group were best fitted by a two-factor model. Factor I included 44 items and Factor II included 16. Most items showed similar tendencies, except for two. Item 29 was included in both Factor I and II and item 33 in Factor II in the EFA on the entire sample, whereas both items were included in Factor II in the
EFA for the group of subjects without a comorbidity.

\section{Analyses of Factor I and II scores}

According to the correlation analyses on the factor scores (Table 4), Factor I was very strongly correlated with the A-GBI depressive subscale $(r=0.990, p<0.001)$, and Factor II with the A-GBI hypomanic/biphasic subscale $(r=0.877, \mathrm{p}<0.001)$. The correlation analyses which were conducted to examine the relationships between factor scores and other scales showed that Factor I was strongly correlated with RCMAS ( $r=0.666$, $\mathrm{p}<0.001)$ and CDI $(\mathrm{r}=0.764, \mathrm{p}<0.001)$. However, Factor II was weakly correlated with other assessment tools, whereas A-GBI hypomanic/biphasic subscale was moderately correlated with RCMAS $(\mathrm{r}=0.570, \mathrm{p}<0.001)$ and CDI $(\mathrm{r}=0.550, \mathrm{p}<0.001)$.

Next, factor scores were compared among the diagnostic groups (Table 5). Factor I score was significantly higher in the depressive disorder and bipolar disorder groups than in the 
Table 5. Factor scores according to the diagnosis of the mood disorder

\begin{tabular}{lcccccc}
\hline & Depressive $(n=134)$ & Bipolar $(n=53)$ & Non-mood $(n=33)$ & $F$ & $P$ & Post-hoc \\
\hline Factor I & $0.04 \pm 0.91$ & $0.39 \pm 1.01$ & $-0.78 \pm 0.84$ & 15.268 & $<0.001$ & $D, B>N$ \\
Factor II & $-0.12 \pm 0.87$ & $0.38 \pm 1.10$ & $-0.15 \pm 0.86$ & 5.580 & 0.004 & $B>D, N$ \\
\hline
\end{tabular}

Data are mean \pm standard deviation values. B: bipolar disorder group, D: depressive disorder group, N: non-mood disorder group

non-mood disorder group ( $\mathrm{F}=15.268, \mathrm{p}<0.001)$. Furthermore, Factor II score was significantly higher in the bipolar disorder group than in the depressive disorder and non-mood disorder groups $(\mathrm{F}=5.580, \mathrm{p}=0.004)$.

\section{DISCUSSION}

In the present study, EFA was conducted on the Korean version of A-GBI and two common factors were identified from the individual items. Of the 46 items of the depressive subscale, 42 were included in Factor I and 1 in Factor II, and 9 of 28 items of the hypomanic/biphasic subscale were included in Factor I and 12 in Factor II. Therefore, Factor I and Factor II are thought to show similar trends with A-GBI depressive subscale and A-GBI hypomanic/biphasic subscale, respectively. Additionally, the correlation coefficient of Factor I and the depressive subscale of GBI was 0.990 and that of Factor II and the hypomanic/biphasic subscale of GBI was 0.877 , indicating that each of the pairs has a very strong positive correlation. These findings are consistent with a previous finding that two factors, depressive and hypomanic/biphasic, were identified using GBI in youths [19]. The present study demonstrated that the Korean version of A-GBI is constituted of two factors, suggesting a two-dimensional model of mood symptoms in Korean youths.

However, there were discrepancies between the individual items included in Factors I and II of the present study and those of the depressive and hypomaniac/biphasic subscales in the English version of A-GBI. Regarding the English version of A-GBI, items 2, 8, 19, 22, 35, 40, 42, 57, and 66 are in the hypomaniac/biphasic subscale. But in this study, they were included under Factor I, a factor representing depressive mood. These items are related to rapid mood swings, impulsivity, and the increasing level of perceived mood. Also, items 4, 7, 11, $24,44,51,58,61,65$, and 67 were not included in either factor. These are mainly about euphoric mood or symptoms of seasonal/diurnal mood swings. The discrepancies in the items included in Factors I and II and the depressive and hypomaniac/biphasic subscales may be related to cultural influences. Specifically, mood disorder and relevant symptoms are known to vary among different cultures [20]. The notion of depression has been developed with reference to Western culture and in particular, individuals of Asian culture tend to express more physical symptoms, like insomnia, loss of appetite, and fatigue
[20-22]. The report and interpretation may also differ with respect to manic symptoms [23]. Indeed, previous studies have shown that Koreans more frequently reported symptoms of low energy, concentration difficulty, and poor appetite, and less frequently reported depressed mood and thoughts of death $[20,24]$. The prevalence of bipolar disorder in youths is reported to vary in different countries, as well [25]. However, it should be determined in a future study whether the aforementioned discrepancies in individual items were due to cultural differences or different sizes of the diagnosis group, as the proportion of those experiencing manic or hypomanic episode was very low in this study $(n=4)$.

A-GBI depressive subscale score was higher in the depressive and bipolar disorder groups compared to the non-mood disorder group, and A-GBI hypomaniac/biphasic subscale score was significantly higher in the bipolar disorder group. These findings are in line with previous studies showing that A-GBI is a useful tool for screening mood disorder in youths $[11,12]$. Particularly, both hypomaniac/biphasic subscale and Factor II scores were higher in the bipolar disorder group than in the depressive group. The finding suggests that A-GBI is effective in distinguishing bipolar disorder from depressive disorder.

Item 29, which were included in both Factors I and II, and item 33, which was included in Factor I, were classified to Factor II in the EFA conducted only with the subjects without a comorbidity. Mood disorder in childhood and adolescence is well known to co-occur with diverse psychiatric disorders such as anxiety disorder, ADHD, and substance use disorder [26]. Some subjects in the mood disorder groups in this study also had anxiety disorder, somatic symptoms disorder, and ADHD. Hence, the presence or absence of these comorbidities might have influenced the EFA results. Aside from items 29 and 33, however, most of the other items showed similar trends, and the EFA on the subjects only with mood disorder also confirmed that A-GBI consists of two factors.

The study has the following limitations. First, the study sample may have been biased, as the sample was composed of children and adolescents who visited a single university hospital; subjects visiting a tertiary hospital tend to have more severe symptoms. Future study samples should include community youths. Second, the number of subjects having manic symptoms was low. A-GBI is used to assess both depressive and hypomanic/biphasic symptoms simultaneously, but only 
4 of the study subjects were experiencing manic symptoms. This number was very low in comparison to 162 subjects manifesting depression. Hence, the EFA results may have been influenced by such a wide variation. Third, the data were collected by performing a retrospective chart review, and the diagnosis was determined on the basis of the recorded diagnosis or other records in the patient charts. Thus, diagnostic accuracy could be lower compared to a structured interview like Kiddie Schedule for Affective Disorders and Schizophrenia-Present and Lifetime. Finally, other assessment tools for bipolar mood symptoms were not administered. The relationship between Factor II and bipolarity could be evaluated more accurately by examining the correlations between Factor II and other assessment tools for bipolar symptoms, but no such tools were available in this study. This limitation is believed to be due to the methodology of retrospective chart reviews. More accurate results are expected if, in the future, assessment tools for bipolar mood symptoms are included in prospectively conducted research.

Nevertheless, the study is of significance in that the structure of mood symptoms in Korean youths was examined by performing EFA on the Korean version of A-GBI, and that the Korean version of the tool is found to be useful in assessing mood disorder in youths.

\section{CONCLUSION}

This study was conducted to examine the structure of mood symptoms in Korean youths by conducting EFA on data from Korean youths who self-administered A-GBI. The analysis revealed two mood symptom factors that can be discriminated with the use of the Korean version of A-GBI, a finding in line with a two-dimensional model of the mood symptoms.

\section{Supplementary Materials}

The online-only Data Supplement is available with this article at https://doi.org/10.5765/jkacap.190023.

\section{Acknowledgments}

This work has supported by the National Research Foundation of Korea (NRF) grant funded by the Korean Government (Ministry of Science and ICT) (No. 2018R1A2B6002216).

\section{Conflicts of Interest}

The authors have no potential conflicts of interest to disclose.

\section{Author Contributions}

Conceptualization: Hyo-Won Kim, Han-Sung Lee. Data curation: Hyo-Won Kim, Han-Sung Lee. Formal analysis: Hyo-Won Kim, HanSung Lee. Funding acquisition: Hyo-Won Kim. Investigation: Yejin Kwon, Seung-Hyun Shon, Kee Jeong Park. Writing_original draft: Hyo-Won Kim, Han-Sung Lee. Writing_review \& editing: Yejin Kwon, Seung-Hyun Shon, Kee Jeong Park.

\section{ORCID iDs}

Han-Sung Lee https://orcid.org/0000-0001-5391-6723

Yejin Kwon https://orcid.org/0000-0001-7633-5067

Seung-Hyun Shon https://orcid.org/0000-0002-6782-1423

Kee Jeong Park https://orcid.org/0000-0002-9709-8723

Hyo-Won Kim https://orcid.org/0000-0002-8744-5138

\section{REFERENCES}

1) Kazdin AE. Childhood depression. J Child Psychol Psychiatry 1990;31:121-160.

2) Merikangas KR, He JP, Burstein M, Swanson SA, Avenevoli S, Cui L, et al. Lifetime prevalence of mental disorders in U.S. adolescents: results from the National Comorbidity Survey Replication--Adolescent Supplement (NCS-A). J Am Acad Child Adolesc Psychiatry 2010;49:980-989.

3) Ministry of Gender Equality and Family. The white paper on youth in Korea. Sejong: Ministry of Gender Equality and Family;2016.

4) Geller B, Tillman R, Craney JL, Bolhofner K. Four-year prospective outcome and natural history of mania in children with a prepubertal and early adolescent bipolar disorder phenotype. Arch Gen Psychiatry 2004;61:459-467.

5) Kowatch RA, Youngstrom EA, Danielyan A, Findling RL. Review and meta-analysis of the phenomenology and clinical characteristics of mania in children and adolescents. Bipolar Disord 2005;7: 483-496.

6) Coyle JT, Pine DS, Charney DS, Lewis L, Nemeroff CB, Carlson GA, et al. Depression and bipolar support alliance consensus statement on the unmet needs in diagnosis and treatment of mood disorders in children and adolescents. J Am Acad Child Adolesc Psychiatry 2003;42:1494-1503.

7) Goldstein TR, Birmaher B, Axelson D, Ryan ND, Strober MA, Gill MK, et al. History of suicide attempts in pediatric bipolar disorder: factors associated with increased risk. Bipolar Disord 2005; 7:525-535.

8) Rudolph KD, Lambert SF. Child and adolescent depression. In: Mash EJ, Barkley RA, editors. Assessment of childhood disorders. New York: Guilford Press;2007. p.213-252.

9) Depue RA, Krauss S, Spoont MR, Arbisi P. General behavior inventory identification of unipolar and bipolar affective conditions in a nonclinical university population. J Abnorm Psychol 1989; 98:117-126.

10) Youngstrom EA. Pediatric bipolar disorder. In: Mash EJ, Barkley RA, editors. Assessment of childhood disorders. New York: Guilford Press;2007. p.253-304.

11) Lee HJ, Joo Y, Youngstrom EA, Yum SY, Findling RL, Kim HW. Diagnostic validity and reliability of a Korean version of the parent and adolescent general behavior inventories. Compr Psychiatry 2014;55:1730-1737.

12) Danielson CK, Youngstrom EA, Findling RL, Calabrese JR. Discriminative validity of the general behavior inventory using youth report. J Abnorm Child Psychol 2003;31:29-39.

13) Youngstrom EA, Frazier TW, Demeter C, Calabrese JR, Findling RL. Developing a 10-item mania scale from the parent general behavior inventory for children and adolescents. J Clin Psychiatry 2008;69:831-839.

14) Reynolds CR, Richmond BO. What I think and feel: a revised measure of children's manifest anxiety. J Abnorm Child Psychol 1978; 6:271-280.

15) Choi JS, Cho SC. Assessment of anxiety in children: reliability and validity of revised children's manifest anxiety scale. J Korean Neuropsychiatr Assoc 1990;29:691-702.

16) Kovacs M, Beck AT. An empirical-clinical approach toward a definition of childhood depression. Depression in childhood: diagno- 
sis, treatment, and conceptual models. New York: Raven Press;1977.

17) Beck AT, Ward CH, Mendelson M, Mock J, Erbaugh J. An inventory for measuring depression. Arch Gen Psychiatry 1961;4:561-571.

18) Cho SC, Lee YS. Development of the Korean form of the Kovacs' children's depression inventory. J Korean Neuropsychiatr Assoc 1990;29:943-956.

19) Youngstrom EA, Findling RL, Danielson CK, Calabrese JR. Discriminative validity of parent report of hypomanic and depressive symptoms on the general behavior inventory. Psychol Assess 2001;13:267-276.

20) Kirmayer LJ, Groleau D. Affective disorders in cultural context. Psychiatr Clin North Am 2001;24:465-478, vii.

21) Kleinman AM. Depression, somatization and the "new cross-cultural psychiatry." Soc Sci Med 1977;11:3-9.

22) Ryder AG, Yang J, Zhu X, Yao S, Yi J, Heine SJ, et al. The cultural shaping of depression: somatic symptoms in China, psychological symptoms in North America? J Abnorm Psychol 2008;117:300313.

23) Mackin P, Targum SD, Kalali A, Rom D, Young AH. Culture and assessment of manic symptoms. Br J Psychiatry 2006;189:379-380.

24) Chang SM, Hahm BJ, Lee JY, Shin MS, Jeon HJ, Hong JP, et al. Cross-national difference in the prevalence of depression caused by the diagnostic threshold. J Affect Disord 2008;106:159-167.

25) Soutullo CA, Chang KD, Díez-Suárez A, Figueroa-Quintana A, Escamilla-Canales I, Rapado-Castro M, et al. Bipolar disorder in children and adolescents: international perspective on epidemiology and phenomenology. Bipolar Disord 2005;7:497-506.

26) Martin A, Volkmar FR, Lewis M. Lewis's child and adolescent psychiatry: a comprehensive textbook. Philadelphia: Lippincott Williams \& Wilkins;2007. 


\section{Total subjects Subjects without}

Item $\quad(\mathrm{n}=220) \quad$ comorbidities

\section{$0.59 \quad 0.51 \quad$ Have there been periods, over the last year, when it was almost impossible to make small decisions even though this may not be generally true of you?}

$0.56 \quad 0.58$

0.8

0.46

0.76 Have you become sad, depressed, or irritable for several days or more without really understanding why? Have you experienced periods of several days or more when, although you were feeling unusually happy and intensely energetic (clearly more than your usual self), you were also physically restless, unable to sit still, and have to keep moving or jumping from one activity to another? Have there been periods of sever or heavy work schedules?

Have there been periods of several days or more when you were almost constantly active such that others told you they couldn't keep up with you or that you wore them out? Have there been times when your memory or concentration seemed especially poor and you found it difficult, for example, to read or follow a TV program, even though you tried? Have there been times when you lost almost all interest in the things that you usually like to do (such as hobbies, school, work, entertainment)? Have you had periods of sadness and depression when almost everything gets on your nerves and makes you irritable or angry (other than related to the menstrual cycle)?

0.44 Have there been times of several days or more when you did not feel the need for sleep and were able to stay awake and alert for much longer than usual because you were full of energy? Have there been times of several days or more when you did not feel the need for sleep and were ab
Have you had long periods in which you felt that you couldn't enjoy life as easily as other people?

$0.42 \quad 0.4$ Have you had periods of several days or more when you wanted to be with people so much of the time that they asked you to leave them alone for a while?

0.47 Have there been times of several days or more when you were so tired and worn out that it was very difficult or even impossible to do your normal everyday activities (not including times of intense exercise, physical illness, Have there been periods lasting several days or more when you spent much your time brooding about unpleasant things that have happened? Have there been times when you felt that you were physically cut off from other people or from yourself, or felt as if you were in a dream, or felt that the world looked different or had changed in some way? Have you had periods of extreme happiness and intense energy lasting several days or more when you also felt much more anxious or tense (jittery, nervous, uptight) than usual (other than related to the menstrual cycle)? Have there been times of several days or more when you were so sad that it was quite painful for you, or you felt that you couldn't stand it?

0.42 Have you found that your enjoyment in eating changes - from periods of two or more days when food tastes exceptionally good, clearly better than usual, to other periods of several days or more when food seems rather flavorless and perhaps you don't enjoy eating at all?

Have there been times of several days or more when you wake up much too early in the morning and have problems getting back to sleep? Have there been times of several days or more when you wake up much too early in the morning and have problems getting bo
Have you had periods when you were so down that you found it hard to start falking or that falking took too much energy?

0.52 Have there been times of several days or more when, although you were eling unusually happy and intensely energetic (clealy or an urge to smash or destroy things? (d) aches and pains; (e) nausea, vomiting, or stomach aches; (f) blurred vision; (g) trembling or shaking hands; or (h) feeling too hot or too cold?

0.47 Have you experienced periods of several days or more when were feeling down and depressed, and you also were physically restless, unable to sit still. a

0.59 Have there been times lasting several days or more when you felt you must have lots of excitement, and you actually did a lot of new or different things?

0.62 Have you had periods of extreme happiness and intense energy (clearly more than your usual self) when for several days or $m$ Over the past year, have there been times when you looked back over your life and could see only failures or hardships?

0.45 Have you experienced times of several days or more when you felt as if you were moving in slow motion? Have there been long periods over the last year when you felt sad, depressed, or irritable most of the time? Has it seemed that you experience both pleasurable and painful emotions more intensely than other people? Have there been periods of several days or more when you felt guilty and thought you deserved to be punished for something you had or had not done? Have you had times of several days or more when you woke up frequently or had trouble staying asleep during the middle of the night?

0.65 Have you had periods of extreme happiness and high energy lasting several days or more when what you saw, heard, smelled, tasted, or touched seemed vivid or intense? Have there been times when you were feeling low and depressed, and you also had to struggle very hard to control inner feelings of rage or an urge to smash or destroy things? Have you found that your feelings or energy are generally up or down, but arely in the middle? Have you had periods of several days or more when it was difficult or almost impossible to think and your mind felt sluggish, stagnant, or "dead"? Have there been times when you had a strong urge to do something mischievous, destructive, risky, or shocking?

0.51 Have there been periods of several days or more when your thinking was so clear and quick that it was much better than most other people's? Have there been times when you exploded at others and afterwards felt bad about yourself? Over the past year, have there been times of several days or more when you were so down that nothing (not even friends or good news) could cheer you up? 0.5 Have there been times of several days or more when you felt that you were a very important person or that $y$
Have there been times when you hated yourself or felt that you were stupid, ugly, unlovable, or useless?

0.57 Have you found that your thinking changes greatly - that there are periods of several days or more when you think better than most people, and other periods when your mind doesn't work well at all? Have there been times of a day or more when you had no feelings or emotions and seemed cut off from other people?

Have you had sad and depressed periods lasting several days or more when you also felt much more anxious or tense (jittery, nervous, uptight) than usual (other than related to the menstrual cycle)?

0.41 Have there been times when you have done things - like perhaps driving recklessly, taking a trip on the spur of the moment, creating a public disturbance, being more sexually active than usual, getting into fights, destroying property, or getting into trouble with the law - which you later thought showed poor judgment?

$0.61 \quad H a v e$ you had periods of sadness and depression when, for several days or more, it took you over an hour to get to sleep at night, even though you were very tired?

$0.5 \quad 0.59$ Have you had periods lasting several days or more when you felt depressed or irritable, and then other periods of several days or more when you felt extremely high, elated, and overflowing with energy? Have there been times of several days or more when you really got down on yourself and felt worthless? Have there been times when you had blank spells in which your activities were interrupted, and you did not know what was going on around you? Have you had sad and depressed periods of several days or more, interrupted by periods lasting between an hour to a day when you felt extremely happy and intensely energetic? Have you had sad and depressed periods of several days or more, interrupted by periods lasting between an hour to a day Have you experienced weight changes (increases, decreases, or both) of five pounds or more in short periods of time (three weeks or less), not including changes due to physical illness, menstruation, exercise, or dieting? Have there been periods of a couple days or more when your sexual feelings and thoughts were almost constant, and you couldn't think about anything else? Have you had periods when it seemed that the future was hopeless and things could not improve? Have there been periods lasting several days or more when you were so down in the dumps that you thought you might never snap out of it?

0.5 Have you had times when your thoughts and ideas came so fast that you couldn't get them all out, or they came so quickly others complained that they couldn't keep up with your ideas? Have there been times of several days or more when you felt very down and depressed during the early part of the day, but then less so during the evening? Have then been times when you began many new activities with lots of enthusiasm and then found yourself quickly losing interest in them? Have you found that your mood consistently follows the seasons, where you have long periods of depression during the winter but mostly happy periods during the summer? Have you had long periods when you were down and depressed, interrupted by brief periods when your mood was normal or slightly happy? Have there been times of several days or more when you have struggled to control an urge to cry, have had frequent crying spells, or found yourself crying without really understanding why (other than related to the menstrual cycle)? Have there been times of several days or more when almost all sexual interest was lost? Have you found yourself at times feeling fearful or suspicious of your environment or people around you? Have there been periods of time when you felt a persistent sense of gloom? Have there been times when you felt that you would be better off dead? 